\title{
Effect of recycled water on the soil physical-chemical properties of four vineyards in Great Western, Victoria, Australia
}

\author{
K. Hermon ${ }^{1,2}$, G. Allinson ${ }^{2}$, P. Maher ${ }^{1}$, F. Stagnitti ${ }^{1}$ \\ \& R. Armstrong ${ }^{3}$ \\ ${ }^{1}$ School of Life and Environmental Sciences, Deakin University, \\ Warrnambool, Victoria, Australia \\ ${ }^{2}$ Future Farming Systems Research, Department of Primary Industries, \\ Queenscliff, Victoria, Australia \\ ${ }^{3}$ Future Farming Systems Research, Department of Primary Industries, \\ Horsham, Victoria, Australia
}

\begin{abstract}
The effect of recycled water on soil physico-chemical properties was investigated in a number of blocks in each of four vineyards in the Great Western wine growing region, comparing soils beneath vines irrigated with recycled water and/or on-farm dam water with undeveloped land in each case. The application of recycled water in Great Western vineyards since 1999 has impacted deleteriously on the properties of topsoils and to a lesser extent on subsoils. These impacts include an increase in soil electrical conductivity (EC) and soil exchangeable sodium percentage (ESP). The data suggests that there is a significant threat to soil structural integrity from use of the recycled water at all sites. There is a comparable threat from some fresh (dam) water resources used in this region. Risks are either as a result of elevated sodium levels coupled with moderate salinity, or as a result of waters with very low salinity.
\end{abstract}

Keywords: recycled water, salinity, soil solute distribution and impact, vineyard sustainability.

\section{Introduction}

The Great Western wine region of western Victoria, fig. 1, was established during the gold rush era of the 1850s. The area of plantings in the region was 
historically limited by a lack of utilizable water, with resources restricted to surface storage dams only, as groundwater and surface water resources are saline. In 1999, the Grampians Wimmera Mallee Water Authority completed its construction of a 17 kilometre pipeline from the Ararat Wastewater Treatment Plant. The pipeline is designed to deliver at least $600 \mathrm{ML}$ of recycled water a year to vineyards in the Great Western region, and provides the water authority with an alternative option for the disposal of wastewater (to discharging to the nearby Hopkins River), while at the same time, providing vineyards in the Great Western region with the opportunity to expand existing plantings.

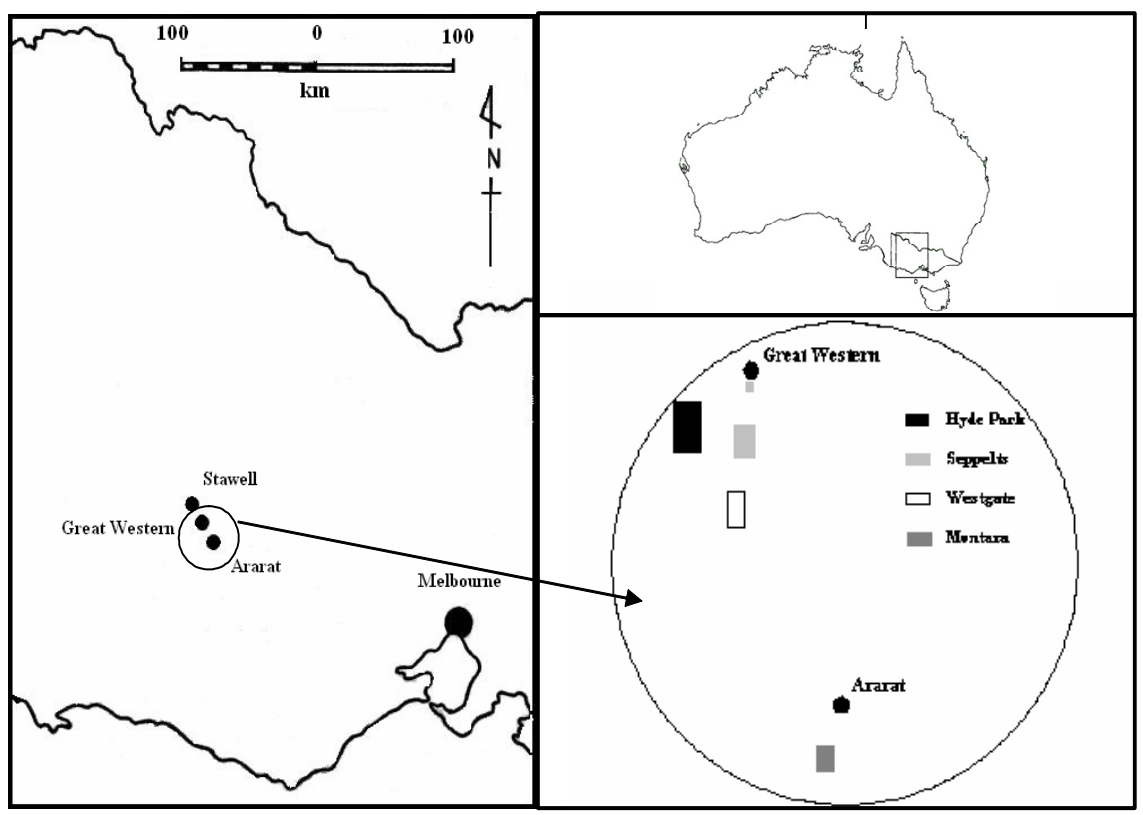

Figure 1: Location of sampling sites within the Great Western region of Victoria.

The substitution of fresh water with recycled water is an increasingly accepted practice, and stems from the realisation that wastewater must not be viewed as a liability, but rather, a valuable resource. Given that irrigated agriculture accounts for some $85 \%$ of all water consumption worldwide, and some $67 \%$ in Australia in 2001 [1], agricultural use of recycled water has the potential to liberate significant quantities of water [2]. However, there are a range of environmental problems that can arise from the use of recycled water, such as increased sodicity, recharge of groundwater leading to the development of salinity, contamination of soil and groundwater by metals and organic chemicals, and eutrophication of local surface waters.

Salinity and sodicity management is critical for all irrigation schemes, including those using recycled water. Consequently, this study was developed to provide local grape growers with an insight into the potential long-term 
consequences of using recycled water in the Great Western region's vineyards. Specifically, the aim of this project was to investigate the impact of recycled water irrigation on sub soil conditions by assessing the effect of recycled water on soil resources, specifically sodicity and salinity.

\section{Materials and methods}

\subsection{The Great Western region}

The study area for this project is the Great Western wine growing region in western Victoria $\left(37^{\circ} 09^{\prime} \mathrm{S}, 142^{\circ} 51^{\prime} \mathrm{E}\right.$; fig. 1), located $220 \mathrm{~km}$ NW of Melbourne at an elevation of 280 to $360 \mathrm{~m}$ above sea level (ASL) [3].

The study area falls within the Western Highlands physiographic division of Victoria [4]. The region is defined in terms of geomorphology as consisting of hills and plains of maturely dissected rocks of Palaeozoic origin, with the predominant landforms being undulating plains, rolling plains, and hills [5]. The geology of the region dates back to the middle to upper Cambrian and the lower Ordivician periods, and comprises sedimentary and metamorphosed sedimentary rocks. Dominant rock types include marine unfossiliferous sandstone, mudstone, shale, and slate. Granites and granodiorites of mostly Devonian origin are scattered about the region [6].

The soils consist predominantly of hard, acidic, duplex soils with yellow clay subsoils on the flats, and hard, duplex soils with red clay subsoils on the slopes. Soils are broadly characterised by an acidic to neutral $\mathrm{pH}$, a moderate level of fertility, and moderate subsoil drainage [7].

The climate at Great Western is continental, with slightly winter dominant rainfall (mean maximum and minimum temperatures 18.8 and $6.9^{\circ} \mathrm{C}$, respectively. Mean rainfall, $603 \mathrm{~mm}[7,8]$ ). Property records for Westgate Vineyard indicate that rainfall is distributed in descending order from winter (Jun-Aug, 31\%), to spring (Sep-Nov, 28\%), autumn (Mar-May, 25\%) and summer (Dec-Feb, 17\%) [9]. Evaporation is moderate, as are radiation and relative humidity. There is the risk of frosts during spring.

\subsection{Vineyard sites}

Within the Great Western region, four vineyards were chosen that rely wholly or partially on recycled water for irrigation of vines, namely Hyde Park Vineyard and Seppelts Great Western vineyards in Great Western, Westgate Vineyard in Armstrong, and Montara Winery in Ararat. The vineyards were chosen for the study because they represent the range of differing soils types, management practices, and irrigation histories representative of the region.

\subsubsection{Hyde Park Great Western Vineyard (datum points 1-4)}

Hyde Park vineyard was planted in 1998 with predominantly Shiraz (clones 1127, PT23, and 1654, all on own rootstock), and Cabernet Sauvignon (clones LC10, LC14) [10]. Drip irrigation is employed in this vineyard, delivering 1-1.5 $\mathrm{ML} / \mathrm{ha} / \mathrm{yr}$. The majority of the vineyard is irrigated with recycled water although a small section is irrigated with fresh (dam) water. 
The soils in Sweeney's (datum point (DP) 1), Lynd's (DP 2), and Daly's Blocks (DP 3) are described as Duplex Yellowish Brown Clays, comprising a sandy loam topsoil over a hard, mottled clay [10]. The topsoils are structurally poor, with a tendency to slake indicating poor resilience to traffic and a tendency to seal. The abrupt topsoil/subsoil interface presents a barrier to both root penetration and drainage, resulting in a periodically perched water table. The Effective Root Depth (ERD) is low $(380 \mathrm{~mm})$. The subsoil exhibits few pores or cracks, possibly as a result of its tendency to disperse. The soils are acidic ( $\mathrm{pH}$ $\mathrm{CaCl}_{2}$ of $<5$ ), marginally sodic to sodic (SAR of $\geq 6$ ), with a low (1-2) to very low $(<1) \mathrm{Ca}: \mathrm{Mg}$ ratio, low phosphorus content, and potentially low potassium content [10]. Total available water content is low (65-70 mm PAW), suggesting that vines would struggle to obtain sufficient water without development of extensive root systems [10].

The soils of Dalberti's Block (datum point 4) are described as a complex of Gradational Reddish Brown Clays and Duplex Reddish Brown Clays, with outcrops of sedimentary siltstone and basaltic rock. On the hills and ridges, the red gradational soils are relatively shallow $(400-700 \mathrm{~mm})$, becoming deeper on the midslopes, although the subsoils are not as well structured. Gradational soils give way to Duplex Reddish Brown Clays on the lower portions of the block. The duplex clays are unstable, poorly structured, with bleached subsurface layers indicating a perched water table. Effective Root Depth was calculated to be adequate (about $790 \mathrm{~mm}$ ) [10].

\subsubsection{Seppelts Great Western Vineyard (datum points 5-8)}

Vines in Arawatta block, bays 5 and 6 (DPs 5 and 6) are Shiraz 1654, own rooted, whilst those in Arawatta block bay 7 (DP 7) are Shiraz St Peters/R110. The vines were planted in 1998, and are drip irrigated with recycled water with the exception of Bay 6.1 (DP 6), which is irrigated with dam water when available. Recycled water was applied to this bay in the $2002 / 3$ season due to drought conditions. A reconnaissance soil survey conducted prior to planting described the soils as suitable for development while recognising the following limitations: low $\mathrm{pH}$ and associated nutrient deficiency problems; reduced infiltration of the surface layer; localised ponding and run-off; and subsurface water accumulation and lateral flows. Vertically tilted parent material (siltstone) combined with a friable and well structured subsoil is considered indicative of good aeration and permeability [11]. Rootzone readily available water (RAW) in the vicinity of the chosen bays $(5,6 \& 7)$ was found to range from $47-58 \mathrm{~mm}$, which is within an optimum range.

St Peters block (DP 8) was planted with Shiraz vines approximately 80 years ago, and is drip irrigated with dam water. The dominant soils were described as Stawell Sandy Loams and Stawell Sandy Clay Loams [9]. These are yellow duplex soils, with near neutral pH, a bleached A2 horizon, and a mottled, medium to heavy clay subsoil.

\subsubsection{Westgate Vineyard (datum points 9-10)}

Westgate Vineyard comprises some 13 hectares of vines. Eight hectares of Riesling vines were dry planted in 1969, with irrigation via sprinkler introduced 
in 1982, using water from an old gold mine shaft on the property. A further 5 hectares of Shiraz vines planted in the late 1990s, along with much of the existing block utilise recycled water by drip irrigation. A small section of the existing vineyard remains under fresh water irrigation. Drip irrigation of recycled water is managed by applying approximately $2 \mathrm{ML} / \mathrm{ha}$ over five or six irrigations, while sprinkler irrigation of mine water delivers approximately 0.7 ML/ha via three irrigation events per season. Datum points 9 and 10 are located in the block planted to Riesling in 1969, which is partially irrigated with fresh water using sprinklers, the remainder being irrigated with recycled water by drip irrigation.

Soils at Westgate were surveyed in 1980 [9], and are very complex in their distribution. In general, red gradational soils predominate in the highest parts of the property, while the lower areas, which include the vineyard, are comprised of red duplex soils, with yellow duplex soils occurring in the depressions and gullies. Datum points 9 and 10 were positioned on the red duplex soils, described by Badawy [9] as a complex of Great Western sandy clay loam (Dr 3.41/SCL "gr" (40 cm)), and Concongella sandy clay loam (deep surface and stony profile) (e.g. Dr 2.42/FSCL (45cm)). Concongella sandy clay loams are red duplex soils with a deep, bleached A2 horizon, a moderately to strongly pedal, medium to heavy clay subsoil, and small amounts of shale, quartz, and ferruginous concretions throughout the profile. The Great Western sandy clay loams differ in that the subsoils are mottled, and the bleaching of the A2 horizon is sporadic [9].

\subsubsection{Montara Winery (datum point 11)}

Montara Winery, located in Ararat, has been irrigated with recycled water from the Ararat Wastewater Treatment Plant since 1972. The block chosen for this study (DP 11) is planted with 28 year old Riesling vines, which have been irrigated with recycled water via drip irrigation since planting.

The soil type in the chosen block at Montara Winery is a complex of red duplex soils with yellow duplex soils occurring in the depressions. The soils comprise sandy clay loam topsoil over mottled medium to heavy clay subsoil (red or yellow). A conspicuously bleached A2 horizon is present [12].

\subsection{Experimental design}

A fence-line experimental design was chosen for the study whereby adjacent treatments were sampled for comparison. This type of experimental design, often used in agricultural research, allows comparisons to be made between adjacent blocks/paddocks on the same soil types, but under differing management regimes. The vineyards in this study are already under established irrigation management practices, and therefore, the siting of the DPs was determined according to the existing management practices. Consequently, the field studies involved a series of planned comparisons between three treatments:

1. recycled water irrigation (dominant application),

2. fresh water irrigation (where practiced), and

3. pasture/no irrigation (pasture areas adjacent to vineyard, not irrigated). 
Eleven DPs across the four vineyards were chosen for the study. The pasture areas adjacent to vines (treatment 3) were incorporated to provide a baseline or control for the study, allowing inherent background soil properties to be determined. Coupled with comparisons between recycled water (treatment 1) and freshwater irrigation (treatment 2), the study aimed to identify (a) the impacts of vineyard establishment and irrigation on soil properties, (b) the impacts of water quality on soil properties and vine health and productivity, and (c) the potential rate of change in soil properties under long term irrigation with recycled water. Comparison of the results from treatments 1 and 2 , with that of treatment 3 , allows the impacts of vineyard establishment and irrigation management to be identified. Comparison of results between treatments 1 and 2 allows the impacts of recycled water quality on soil properties to be specified.

Table 1: $\quad$ Summary of treatments investigated at each vineyard.

\begin{tabular}{|l|c|l|c|c|c|}
\hline Vineyard & D.P. & Block name & \multicolumn{3}{|c|}{ Treatments investigated } \\
\hline & & & R & F & P \\
\hline & 1 & Sweeney's & $\checkmark$ & $\checkmark$ & $\checkmark$ \\
\hline & 2 & Lynd's & $\checkmark$ & $\mathbf{x}$ & $\checkmark$ \\
\hline & 4 & Daly's & $\checkmark$ & $\mathbf{x}$ & $\checkmark$ \\
\hline Seppelts & 5 & Arrawatta-Bay 5\&6 & $\checkmark$ & $\checkmark$ & $\checkmark$ \\
\hline & 6 & Arrawatta-Bay 5 & $\checkmark$ & $\mathbf{x}$ & $\checkmark$ \\
\hline & 7 & Arrawatta-Bay 7 & $\checkmark$ & $\mathbf{x}$ & $\checkmark$ \\
\hline & 8 & St Peters & $\mathbf{x}$ & $\checkmark$ & $\checkmark$ \\
\hline Westgate & 9 & Riesling & $\checkmark$ & $\checkmark$ & $\checkmark$ \\
\hline & 10 & Riesling & $\checkmark$ & $\mathbf{x}$ & $\checkmark$ \\
\hline Montara & 11 & Riesling & $\checkmark$ & $\mathbf{x}$ & $\checkmark$ \\
\hline
\end{tabular}

DP, datum point; $\mathrm{R}$, recycled water; $\mathrm{F}$, freshwater; $\mathrm{P}$, pasture, no irrigation.

\subsubsection{Irrigation water monitoring}

Both the fresh (dam or groundwater) water and recycled water from the Ararat Wastewater Treatment Plant (AWWTP) were sampled monthly during the 20032004 irrigation season. Recycled water quality information was provided by the water authority (GWMWA) for the license point at the final lagoon of the AWWTP. This data was considered satisfactory for studies at Montara Winery where water is drawn directly from the final lagoon for irrigation but not for Seppelts, Westgate, and Hyde Park where water is stored in tanks, a reservoir, and taken from the pipeline respectively. At these sites, samples were collected on five occasions between October 2003 and April 2004. Samples were collected 
from operating drip irrigation systems within the vineyards whenever possible, or from storages and pipelines as necessary.

Sample collection and analysis protocols, including collection, sample container type, preservation requirements, and maximum holding periods, followed EPA recommendations [13]. Physical and chemical analysis of irrigation waters was conducted by Deakin University (Warrnambool) Water Quality Laboratory (National Association of Testing Authorities (NATA) Accredited Laboratory No. 2457) using standard methods [14] for $\mathrm{pH}$, electrical conductivity (EC), total alkalinity (Alk), suspended solids (SS), the major ions $\left(\mathrm{Na}^{+}, \mathrm{K}^{+}, \mathrm{Mg}^{2+}, \mathrm{Ca}^{2+}\right)$, chloride $\left(\mathrm{Cl}^{-}\right)$and sulphate ions $\left(\mathrm{SO}_{4}{ }^{2-}\right)$, total and soluble reactive phosphorus (TP, SRP), total nitrogen, total Kjeldahl nitrogen, and oxidised nitrogen (TN, TKN, OxN), dissolved organic carbon (DOC), and sodium absorption ratio (SAR).

\subsubsection{Soil sample collection and analysis}

Intact soil cores measuring $100 \mathrm{~cm}$ long by $4.6 \mathrm{~cm}$ diameter were collected from the vine row in the recycled and fresh irrigation treatments using a Geoprobe Model 54LT with a GH42 hammer system. Samples were collected from randomly selected locations beneath the dripper line. Samples from adjacent pasture were collected using a trailer-mounted soil sampling rig. In May 2003, a total of 49 cores were collected, and in October 2004 a further 130 soil cores were collected. Each core was divided into increments of 0-10, 10-20, 20-40, 4060, 60-80, and 80-100 cm, respectively. Procedures for the collection, transport, and post-analysis disposal of all soil samples were subject to the conditions of the National Protocol developed to prevent the spread of grapevine phylloxera in Australian vineyards [15].

Soils were air dried at $<40^{\circ} \mathrm{C}$ for at least 7 days before crushing and sieving to $<2 \mathrm{~mm}$ [16]. Standard methods were used to assess the soil physical and chemical parameters. For instance, appropriate methods in Rayment and Higginson [16] were used for $\mathrm{pH}$ (1:5 water), $\mathrm{pH}\left(1: 5\right.$ soil/0.01 $\left.\mathrm{M} \mathrm{CaCl}_{2}\right), \mathrm{EC}$ (1:5 soil:water), exchangeable bases (1:20 soil/1 $\mathrm{M} \mathrm{NH} \mathrm{NH}_{4} \mathrm{Cl}$ @ pH 7.0), exchangeable sodium percentage (ESP) and total organic carbon (TOC). Bulk density was determined using the method of Blake and Hartge [17], while spontaneous dispersion and mechanical dispersion were determined using methods described by Rengasamy et al. [18]. Water soluble ions (cations and anions) were measured using ion chromatography. All increments were analysed for the samples collected in 2003, whilst for those collected in 2004, only the 010 and 40-60 cm increments were analysed to provide an indication of topsoil and upper subsoil properties.

\subsection{Statistical analysis}

To determine whether there were any statistical differences in soil physical and chemical properties between the three treatments, a Mann-Whitney U-test was performed in SPSS for Windows (version 11.5.2.1). The Mann-Whitney U-test compares the median values of two sets of data. This test was chosen as the data did not meet the usual assumptions of typical parametric analyses (e.g. was not normally distributed). 


\section{Results and discussion}

There was little change in water quality the final lagoon of the treatment plant and application at Montara, Seppelts and Westgate vineyards, table 2. There were, however, some differences in the recycled water quality at Hyde Park, e.g. $\mathrm{pH}, \mathrm{EC}$ and SAR were higher than in the WWTP final lagoon, table 2. This can be attributed to retention time in the lagoon located on the site, whereby processes such as precipitation and evaporation are occurring, resulting in a change in chemical properties.

The EC of the recycled water was of 'medium' classification [19], making it suitable for irrigation of moderately salt tolerant crops, including grapes provided the water is not applied to foliage. The concentration of chloride in the recycled water was high enough to pose a potential toxicity risk to vines, particularly as the vines in these vineyards do not have salt tolerant or chloride tolerant rootstocks $[20,21]$. The SAR values of the recycled water indicate a risk of increased soil water SAR and soil ESP. The fresh water at Hyde Park Vineyard was actually of poorer overall quality than the recycled water, with greater variability in water quality observed across the season (table 2), and is an example of the highly variable and sometimes poor quality of the various sources of irrigation waters collectively termed 'fresh' [22]. When the EC of both the fresh and the recycled waters is considered in conjunction with their SAR value, there is a potential risk of soil structural problems [23].

Soil $\mathrm{pH}$ was highly variable, with few significant differences observed between treatments. This may be because there were indeed few differences or that variability was too high for treatment effects to be observed given the power of the analyses, fig. 2. The $\mathrm{pH}$ was, however, significantly higher in the recycled treatment than in the pasture and fresh treatments at Seppelts and Westgate $(p<0.05$ and $p<0.005$ respectively), suggesting that recycled water irrigation has increased topsoil $\mathrm{pH}$ in these vineyards. The $\mathrm{pH}$ of the soil environment affects the availability of minerals, including vital plant nutrients. An increase towards near neutral soil $\mathrm{pH}$ would generally improve nutrient availability, however, an increase towards alkaline conditions, although unlikely, could have significant impacts with regards to soil structural stability and nutritional balance. It is useful to note, however, that the effects of the different water sources on soil $\mathrm{pH}$ is likely to be less significant than any effects resulting from the application of soil chemical amendments [24,25].

A general trend of increasing EC with recycled water irrigation was observed in both 2003 and 2004, fig. 3. At Westgate Vineyard there were no significant differences in topsoil EC between any of the treatments, indicating that irrigation or irrigation water quality has had no impact on topsoil EC. There were, however, differences observed at Hyde Park, Montara, and Seppelts vineyards, where there were significant increases in topsoil $(0-10 \mathrm{~cm}) \mathrm{EC}$ following recycled water irrigation when compared with pasture soils $(\mathrm{p}<0.001, \mathrm{p}<0.005$, and $\mathrm{p}<0.05$, respectively). At Hyde Park there was also a significantly higher topsoil EC in fresh irrigated soils, compared with pasture soils $(p<0.05)$, which is perhaps not surprising given that the fresh water had a similar EC to the recycled 
Table 2: $\quad$ Summary of recycled and fresh water quality (mean $\pm \mathrm{STD}$ ).

\begin{tabular}{|c|c|c|c|c|}
\hline & \multicolumn{4}{|c|}{ Location } \\
\hline & \multicolumn{2}{|c|}{ Hyde Park Vineyard } & \multicolumn{2}{|c|}{ Seppelts } \\
\hline & $\mathrm{R}$ & $\mathrm{F}$ & $\mathrm{R}$ & $\mathrm{F}(\mathrm{A})$ \\
\hline $\mathrm{pH}$ & $9.2 \pm 0.8$ & $8.4 \pm 0.5$ & $7.4 \pm 0.4$ & $8.1 \pm 0.6$ \\
\hline $\mathrm{EC}$ & $1800 \pm 160$ & $2500 \pm 1100$ & $1700 \pm 350$ & $700 \pm 520$ \\
\hline SS & $20 \pm 21$ & $47 \pm 37$ & $17 \pm 13$ & $19 \pm 15$ \\
\hline $\mathrm{Cl}^{-}$ & $400 \pm 43$ & $590 \pm 270$ & $360 \pm 110$ & $140 \pm 110$ \\
\hline $\mathrm{SO}_{4}{ }^{2-}$ & $76 \pm 10$ & $56 \pm 21$ & $69 \pm 22$ & $53 \pm 30$ \\
\hline Alk & $300 \pm 16$ & $510 \pm 240$ & $350 \pm 100$ & $130 \pm 60$ \\
\hline $\mathrm{Na}^{+}$ & $300 \pm 40$ & $430 \pm 220$ & $270 \pm 35$ & $100 \pm 80$ \\
\hline $\mathrm{K}^{+}$ & $34 \pm 3$ & $20 \pm 8$ & $35 \pm 13$ & $20 \pm 9$ \\
\hline $\mathrm{Mg}^{2+}$ & $24 \pm 2$ & $45 \pm 24$ & $33 \pm 25$ & $23 \pm 27$ \\
\hline $\mathrm{Ca}^{2+}$ & $14 \pm 5$ & $34 \pm 9$ & $27 \pm 3$ & $15 \pm 7$ \\
\hline $\mathrm{OxN}$ & $1.3 \pm 1.9$ & $2.8 \pm 6.2$ & $3.2 \pm 3.4$ & $1.9 \pm 4.1$ \\
\hline $\mathrm{TN}$ & $3.8 \pm 2.3$ & $4.7 \pm 6.3$ & $6.3 \pm 4.3$ & $3.6 \pm 5.3$ \\
\hline TP & $7.5 \pm 2.0$ & $3.3 \pm 7.1$ & $12.2 \pm 6.9$ & $3.4 \pm 6.8$ \\
\hline SRP & $6.0 \pm 2.9$ & $3.0 \pm 6.7$ & $12.0 \pm 7.0$ & $3.2 \pm 6.9$ \\
\hline SAR & $11.5 \pm 2.0$ & $11.1 \pm 3.4$ & $8.7 \pm 1.9$ & $4.0 \pm 3.1$ \\
\hline & Seppelts & & & Montara * \\
\hline & $\mathrm{F}$ (StP) & $\mathrm{R}$ & $\mathrm{F}$ & $\mathrm{R}$ \\
\hline $\mathrm{pH}$ & $8.3 \pm 0.5$ & $7.6 \pm 0.5$ & $7.8 \pm 0.1$ & $8.0 \pm 0.4$ \\
\hline $\mathrm{EC}$ & $140 \pm 20$ & $1400 \pm 140$ & $1200 \pm 140$ & $1300 \pm 120$ \\
\hline $\mathrm{SS}$ & $18 \pm 6$ & $12 \pm 5.4$ & $1.5 \pm 0.4$ & $13 \pm 9$ \\
\hline $\mathrm{Cl}^{-}$ & $13 \pm 5$ & $280 \pm 30$ & $300 \pm 44$ & \\
\hline $\mathrm{SO}_{4}{ }^{2-}$ & $10 \pm 9$ & $68 \pm 17$ & $32 \pm 3$ & \\
\hline Alk & $79 \pm 19$ & $250 \pm 40$ & $170 \pm 20$ & \\
\hline $\mathrm{Na}^{+}$ & $32 \pm 33$ & $230 \pm 20$ & $160 \pm 20$ & $200 \pm 5.8$ \\
\hline $\mathrm{K}^{+}$ & $9 \pm 1$ & $35 \pm 2$ & $5.9 \pm 0.6$ & \\
\hline $\mathrm{Mg}^{2+}$ & $5 \pm 1$ & $15 \pm 2$ & $36 \pm 3$ & $13 \pm 1$ \\
\hline $\mathrm{Ca}^{2+}$ & $5 \pm 1$ & $24 \pm 3$ & $15 \pm 2$ & $19 \pm 2$ \\
\hline $\mathrm{OxN}$ & $0.2 \pm 0.3$ & $5.2 \pm 3.7$ & $0.02 \pm 0.02$ & $7.3 \pm 3.4$ \\
\hline $\mathrm{TN}$ & $2.7 \pm 2.3$ & $7.4 \pm 4.5$ & $1.1 \pm 0.2$ & $15.6 \pm 6.4$ \\
\hline $\mathrm{TP}$ & $4.8 \pm 10.2$ & $15 \pm 2.9$ & $0.3 \pm 0.5$ & $14 \pm 3.5$ \\
\hline SRP & $<\mathrm{LOD}$ & $14 \pm 2.9$ & $0.02 \pm 0.0$ & \\
\hline SAR & $2.3 \pm 2.2$ & $9.1 \pm 0.6$ & $5.2 \pm 0.5$ & $8.7 \pm 0.3$ \\
\hline
\end{tabular}

All units $\mathrm{g} / \mathrm{m}^{3}$ unless unit-less except EC $(\mu \mathrm{S} / \mathrm{cm}) ; \mathrm{n}=5$ in all cases; R, recycled water; F, fresh (dam or ground) water; F (A), Arrawatta block; F (StP), St Peters block; * Ararat WWTP water quality data; LOD, limit of determination.

water. The soils irrigated with freshwater at Hyde Park are also downslope of those irrigated with recycled water, perhaps making them susceptible to subsurface lateral flow from soils irrigated with recycled water. In contrast, 
irrigation with fresh water at Seppelts has resulted in a decrease in topsoil EC, with a significantly lower topsoil EC in the fresh irrigated soil than the pasture soils $(\mathrm{p}<0.05)$, most likely as a result of the low EC of the fresh water.

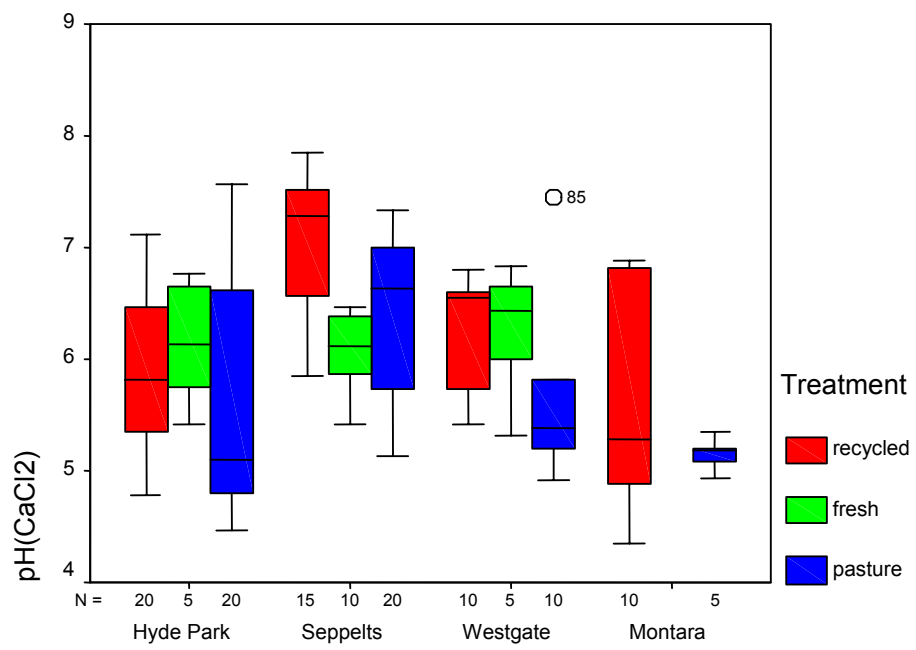

a)

Vineyard

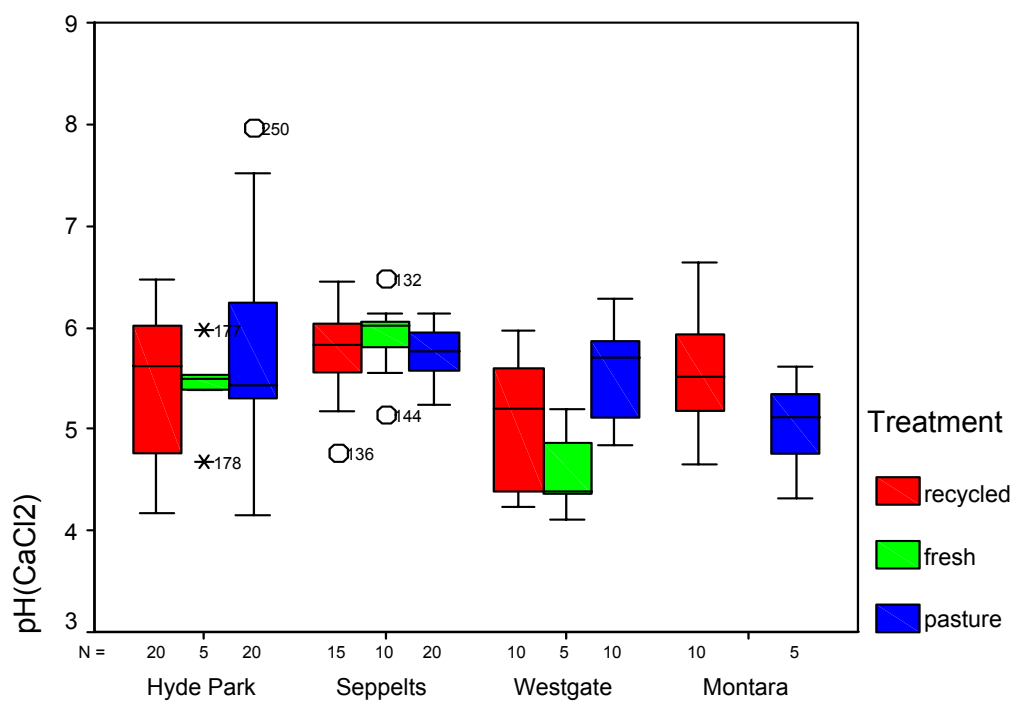

b)

Vineyard

Figure 2: $\quad$ Summary of soil $\mathrm{pH}$ observed across the three treatments (a) topsoil, and (b) sub-soil. 


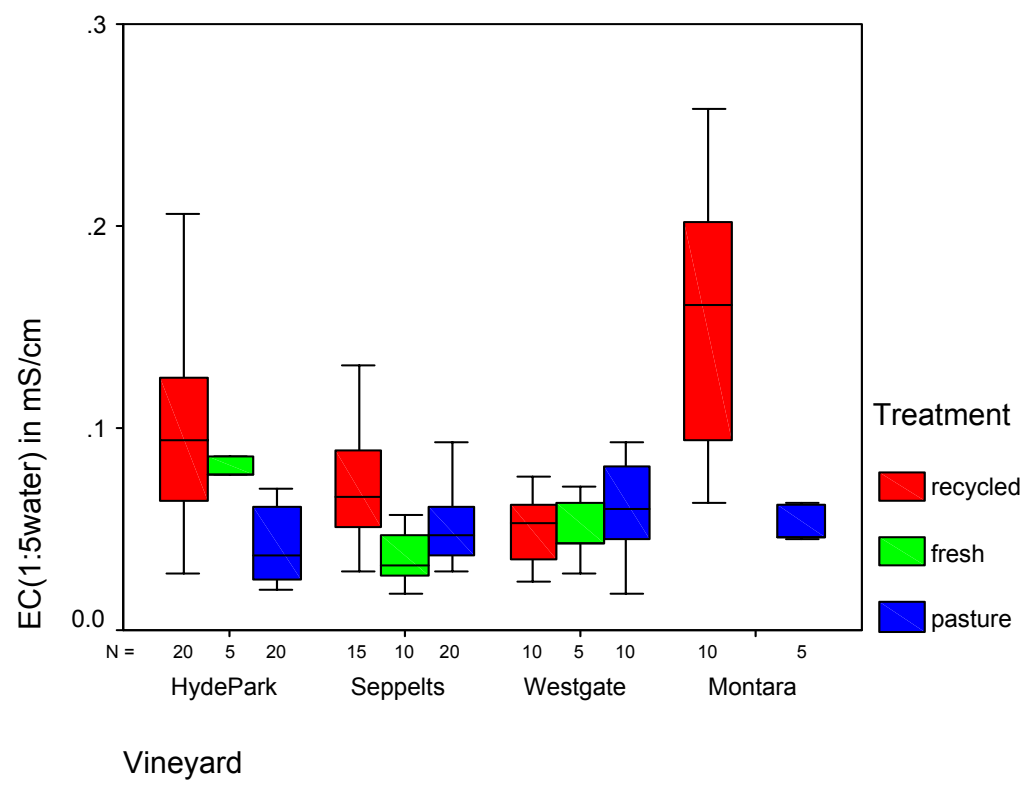

a)

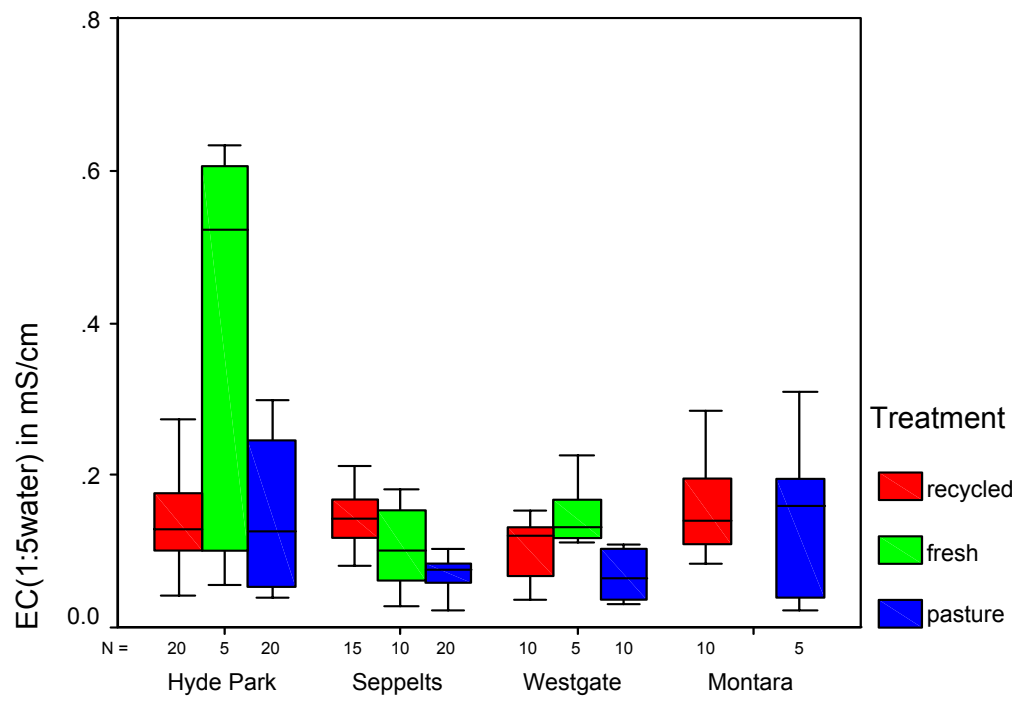

Vineyard

b)

Figure 3: $\quad$ Summary of soil EC observed across the three treatments (a) topsoil, and (b) sub-soil. 


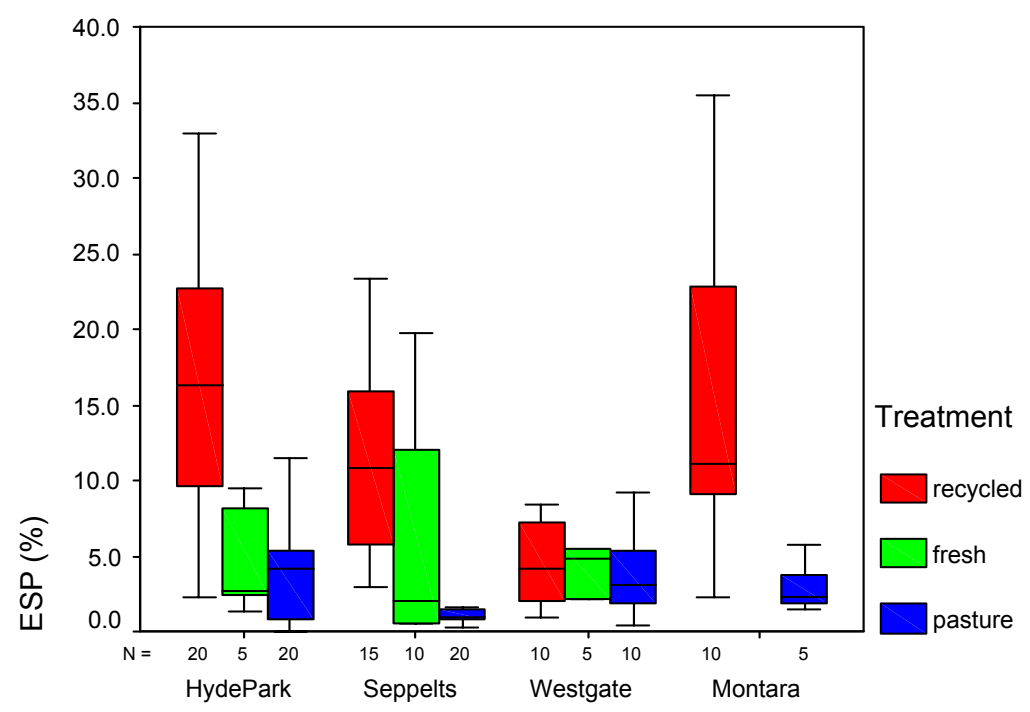

Vineyard

a)

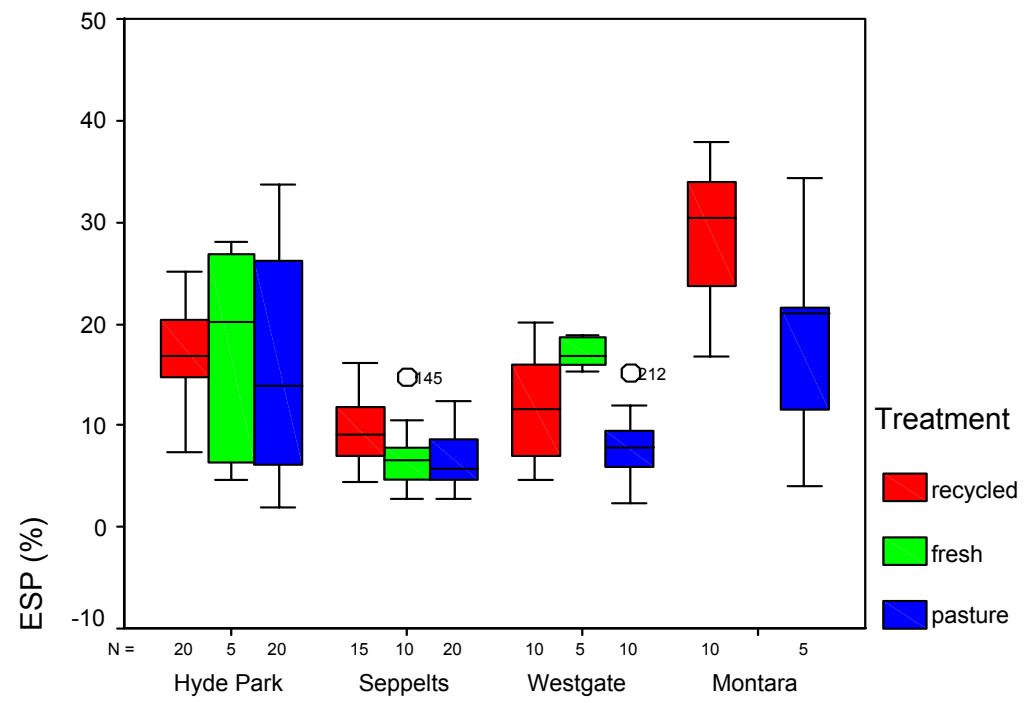

Vineyard

b)

Figure 4: $\quad$ Summary of soil ESP observed across the three treatments (a) topsoil, and (b) sub-soil. 
The use of recycled water does not appear to have impacted on sub-soil EC at Hyde Park or Montara, where no significant differences were observed between treatments. Within subsoils at Seppelts and Westgate, however, highly significant differences were detected between recycled and pasture treatments $(p<0.005$ and $p<0.05$, respectively), indicating that subsoil EC has also increased as a result of recycled water irrigation. Results indicate that subsoil EC at Westgate vineyard has also increased as a result of irrigation with fresh water when compared with pasture soils $(\mathrm{p}<0.005)$. This can possibly be explained by the observation that the EC of the fresh water at this site is similar to that of the recycled water, table 2 .

Whilst the soils in this study are not considered saline, the salinisation of soils over the long term is highly undesirable. In particular, subsoil salinisation is of significant concern due the limited means by which it can be managed. Development of saline conditions in the vineyards of Great Western is an undesirable long-term consequence of wastewater irrigation. The need to manage soil salinity through excess irrigation could be especially problematic at sites such as Hyde Park where groundwaters are particularly shallow as well as saline. There is a real risk of the groundwater rising and causing the saturation and water-logging of the root zone, which could cause a slowing of vine growth, and an increased susceptibility to infection and disease [26]. The upwards movement of water could also mobilise salts leading to secondary salinisation [27]. Elevated soil salts can also result in an increase in the osmotic pressure of the soil water solution, making water extraction by vine roots difficult, leading to water stress and reduced productivity [28]. Soil ESP varied considerably across all three treatments, fig. 4. For instance, at Hyde Park, Seppelts, and Montara, the ESP of topsoils in the recycled water treatment were significantly greater than that those in the pasture treatments $(p<0.001, p<0.001$, and $p<0.005$, respectively). Comparison with soil ESP in the fresh treatments at Hyde Park and Seppelts also indicated a significantly greater ESP as a result of recycled water application $(\mathrm{p}<0.05, \mathrm{p}<0.05$, respectively).

At Hyde Park there were no significant differences between subsoil ESP with the various irrigation treatments. Within the subsoils at Seppelts vineyard, the ESP of soils irrigated with recycled water was significantly greater than that in the pasture soils $(\mathrm{p}<0.05)$. These results indicate that recycled water has also impacted deleteriously on subsoil ESP at this vineyard. At Westgate vineyard, the ESP of subsoils in the fresh irrigated treatment were significantly greater $(p<0.005)$ than that of the pasture treatment soils, indicating that fresh water irrigation has had a greater impact on subsoil ESP than the recycled water. This is possibly a factor of irrigation management at this site, rather than water quality, as the SAR of the fresh water is less than that of the recycled water $(5.5$ \pm 0.5 compared with $9.1 \pm 0.6$ ). It may be a reflection of irrigation technique, for example, as fresh water is applied by sprinkler irrigation at less frequent intervals than the recycled water which is applied by drip irrigation. Smaller volumes of fresh water are also applied over the season, suggesting that leaching of sodium from the rootzone occurs less readily. Further evidence for this conclusion is 
provided by the observation that subsoil EC is also significantly greater in the fresh treatment than in the pasture treatment at this site.

All topsoils irrigated with recycled water, and virtually all subsoils (regardless of treatment) in this study have an ESP $>6$, defining them as sodic [29]. The potential implications of long term application of sodium rich recycled water to these soils include structural decline and associated tendency towards dispersion, such as has been observed in Wagga Wagga, New South Wales [30]. A reduction of soil water infiltration rate and hydraulic conductivity is also of potential concern, as this can lead to temporary waterlogging which in turn can increase surface runoff and erosion [31].

\section{Conclusions}

This study has shown that the application of recycled water in Great Western vineyards since 1999 has impacted deleteriously on the properties of topsoils and to a lesser extent on subsoils. These impacts include an increase in soil electrical conductivity (EC) and soil exchangeable sodium percentage (ESP). The data suggests that there is a significant threat to soil structural integrity from the use of recycled water at all sites. That said, there is a comparable threat from some fresh (dam) water resources used in this region. Risks are either as a result of elevated sodium levels coupled with moderate salinity, or as a result of waters with very low salinity.

\section{Acknowledgements}

The project team would like to acknowledge the financial support provided by the Grape and Wine Research and Development Corporation (GWRDC Project \#DEA 02/01), and the Department of Primary Industries Victoria, Australia (Project \# 08271), and gives its thanks to all the vineyard and water authority personnel, who, in one way or another, contributed to the success of this project.

\section{References}

[1] ABS, Australian wine and grape industry (cat no. 1329.0). Australian Bureau of Statistics, 2002.

[2] Hamilton, A.J., Stagnitti, F., Xiong, X., Kreidl, S.L., Benke, K.K., and Maher, P. Wastewater irrigation: The state of play. Vadose Zone Journal, 6(4), pp. 823-840, 2007.

[3] Gregory, G.R., Development and status of Australian viticulture (Chapter 1). Viticulture. Volume 1: resources, eds. B.G. Coombe and P.R. Dry. Winetitles: Adelaide SA, pp. 1-36, 1988.

[4] Hills, E.S., The physiography of Victoria. 4th Edition, Whitcombe \& Tomb: Melbourne, 1960.

[5] Sibley, G.T., A study of the land in the Grampians area, Soil Conservation Authority: Victoria, 1967. 
[6] Tattam, C.M., Petrology of igneous rocks (Chapter 11). Geology of Victoria, eds. J.G. Douglas and J.A. Ferguson, Publisher: Melbourne, pp. 349-374, 1976.

[7] Beeston, J., The wine regions of Australia. Allen \& Unwin: Crows Nest, Australia, 2002.

[8] Bureau of Meteorology, (2006). Commonwealth of Australia, Bureau of Meteorology. http://www.bom.gov.au. Last accessed: August 2006.

[9] Badawy, N.S., Soils of the vineyards of the Great Western district. Research Project Series No 133, Division of Agricultural Chemistry, Department of Agriculture: Victoria, 1982.

[10] Cass, A., and Dowley, A., Report to Gro-Guard Australia. Soil assessment: viticultural development of Cathcart Ridge vineyard Ararat, Victoria, Alfred Cass and Associates: Calistoga, 1999.

[11] IMT, Reconnaissance soil survey report Arrawatta block Great Western, Victoria for Southcorp Wines Pty Ltd. Irrigation Management Technology Pty Ltd, 1996.

[12] Badawy, N.S., Soils of the vineyards of the Ararat district. Research Project Series No 152, Division of Agricultural Chemistry, Department of Agriculture: Victoria, 1982.

[13] EPA, A guide to the sampling and analysis of waters, wastewaters, soils and wastes. 7th edition. Publication 441, Environment Protection Authority: Victoria, 2000.

[14] APHA, Standard methods for the examination of water and wastewater. 20th Edition. American Public Health Association, American Water Works Association, and Water Environment Federation, 1999.

[15] NVHSC, National Phylloxera management protocol. National Vine Health Steering Committee, 2000.

[16] Rayment, G.E., Higginson, F.R., Australian laboratory handbook of soil and water chemical methods, Inkata: Melbourne, 1992.

[17] Blake, G.R., Hartge, K.H., Bulk density (Chapter 13). Methods of soil analysis, Part 1. Physical and mineralogical methods. Agronomy Monograph no. 9. (Second Edition). ed. A. Klute, American Society of Agronomy, Inc. and Soil Science Society of America, Inc., pp363-375, 1986.

[18] Rengasamy, P., Greene, R.S.B., Ford, G.W., Influence of magnesium on aggregate stability of red-brown earths. Australian Journal of Soil Research, 24, pp. 229-237, 1986.

[19] Stevens, D., Growing crops with reclaimed wastewater. CSIRO Publishing: Melbourne, 2006.

[20] McCarthy, M.G., Jones, L.D., Due, G., Irrigation - principles and practices (Chapter 6). Viticulture Volume 2: Practices, eds. B.G. Coombe, and P.R. Dry, Winetitles: Adelaide, pp. 104-128, 1992.

[21] Rogiers, S., and Creecy, H., Grapevine nutrition. Grapevine Management Guide 2005-06. eds T. Somers and L. Quirk, NSW Department of Primary Industries: Wagga Wagga, 2005. 
[22] Unkovich, M., Kelly, J., Stevens, D., Managing risks to plant health from salinity, sodium, chloride, and boron in reclaimed waters. Growing crops with reclaimed water, ed. D. Stevens, CSIRO Publishing: Collingwood, pp. 304, 2006.

[23] ANZECC, and ARMCANZ, (eds), Australian and New Zealand guidelines for fresh and marine water quality. National Water Quality Management Strategy Paper No. 4, Australian and New Zealand Environment and Conservation Council / Agriculture and Resource Management Council of Australian and New Zealand: Canberra, 2000.

[24] Stevens, D., McLaughlin, M., Owens, G., Kelly, J., Maier, N., Agronomic issues when using reclaimed water: the Northern Adelaide Plains experience. Water Recycling Australia 2000. ed. P. Dillon. CSIRO Land and Water, Australian Water Association, 2000.

[25] Stevens, D.P., McLaughlin, M.J., Smart, M.K., Effects of long-term irrigation with reclaimed water on soils of the Northern Adelaide Plains, South Australia. Australian Journal of Soil Research 41 (5) pp. 933-948, 2003.

[26] NRMMC, EPA, and AHMC, (eds) Australian guidelines for water recycling: managing health and environmental risks (Phase 1).' National Water Quality Management Strategy Paper No. 21, Australian and New Zealand Environment and Conservation Council / Agriculture and Resource Management Council of Australian and New Zealand, 2006.

[27] Bethune, M., Towards effective control of deep drainage under bordercheck irrigated pasture in the Murray Darling Basin: a review. Australian Journal of Agricultural Research 55 pp. 485-494, 2004.

[28] Sumner, M.E., Rengasamy, P., and Naidu, R. Sodic soils: a reappraisal (Chapter). Sodic soils: distribution, properties, management, and environmental consequences, eds. M.E. Sumner and R. Naidu, Oxford University Press: New York, 1998.

[29] Isbell, R.F., The Australian Soil Classification, revised edition. CSIRO Publishing: Melbourne, 1996.

[30] Balks, M.R., Bond, W.J., and Smith, C.J., Effects of sodium accumulation on soil physical properties under an effluent-irrigated plantation. Land application of wastes in Australia and New Zealand: research and practice, Proceedings of Technical Session 14, Australian Conference 29 September - 4 October 1996. eds. P.J. Polgase and W.M. Tunningley, CSIRO Forestry and Forest Products on behalf of the NZ Land Treatment Collective, pp. 195-200, 1996.

[31] Ford, G.W., Martin, J.J., Rengasamy, P., Boucher, S.C., Ellington, A., Soil sodicity in Victoria. Australian Journal of Soil Research. 31, pp. 869-909, 1993. 